Provided for non-commercial research and education use. Not for reproduction, distribution or commercial use.

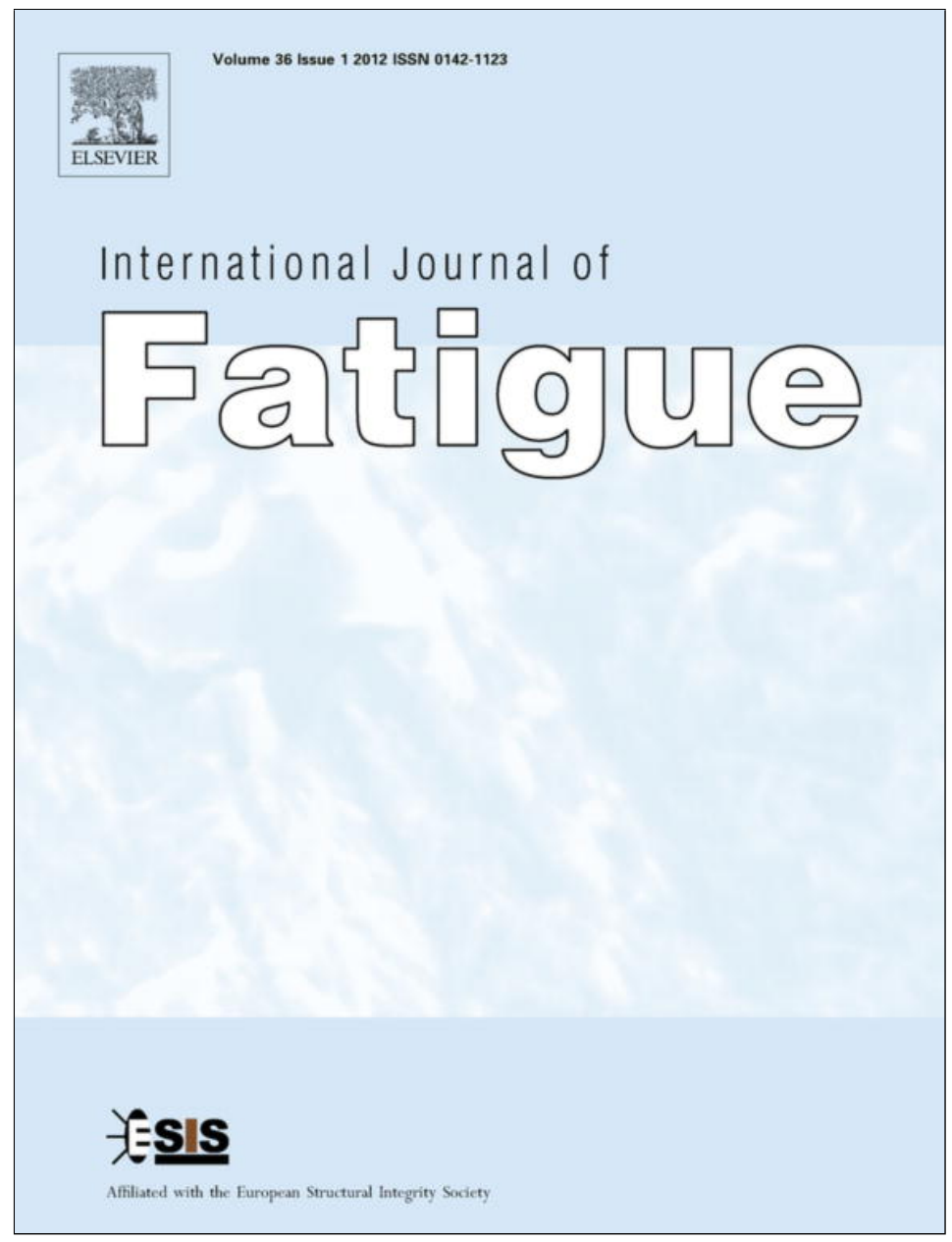

This article appeared in a journal published by Elsevier. The attached copy is furnished to the author for internal non-commercial research and education use, including for instruction at the authors institution and sharing with colleagues.

Other uses, including reproduction and distribution, or selling or licensing copies, or posting to personal, institutional or third party websites are prohibited.

In most cases authors are permitted to post their version of the article (e.g. in Word or Tex form) to their personal website or institutional repository. Authors requiring further information regarding Elsevier's archiving and manuscript policies are encouraged to visit:

http://www.elsevier.com/copyright 


\title{
Effect of tensile residual stresses on fatigue crack growth and $S-N$ curves in tubular joints loaded in compression
}

\author{
C. Acevedo*, A. Nussbaumer \\ ICOM Steel Structures Laboratory, EPFL Swiss Federal Institute of Technology, CH-1015 Lausanne, Switzerland
}

\section{A R T I C L E I N F O}

\section{Article history:}

Received 27 December 2010

Received in revised form 17 July 2011

Accepted 18 July 2011

Available online 23 July 2011

\section{Keywords:}

Welded joints

Fatigue strength

Residual stresses

Fatigue crack growth

Fracture mechanics

\begin{abstract}
A B S T R A C T
The influence of welding tensile residual stresses on fatigue crack growth in bridge tubular K-joints is investigated through experimental testing of large-scale specimens. Crack development is monitored using the alternating current potential drop method. Crack shape, propagation rate, and the stress intensity factors, are analyzed based on measurements. Current CIDECT design guidelines devoted to K-joints recommend to use the fatigue strength $S-N$ curve category 114 . Based on experimental investigations, this category is shown to overestimate the fatigue life of bridge K-joints presenting a low chord slenderness $\gamma$ value $(\gamma<12)$. CIDECT guidelines also neglect fatigue from compressive loading; however, the fatigue test results prove that cracks propagate up to a critical size for details loaded in compression. The detail category 100 is proposed to design bridge K-joints loaded in tension or compression.
\end{abstract}

(C) 2011 Elsevier Ltd. All rights reserved.

\section{Introduction}

During the last 20 years welded tubular truss bridges have become a great success, mainly in Europe. This trend is related to manufacturing techniques which are becoming economically competitive and more easily-accessible. In addition, tubular truss bridges are particularly appreciated and demanded by architects and engineers because of their 'transparent' and aesthetically attractive features, and the advantageous strength of the tubular sections in compression, torsion and bending.

Welded tubular joints are susceptible to fatigue failure [1]. Research addressing these fatigue issues has been carried out during the last 35 years, mainly by the offshore industry [2,3]. Specific research on tubular bridge fatigue started later, in the 1990s. The design specifications used for offshore structures are not appropriate to tubular truss bridges, due to tube dimensions (thick tubes with small diameters lower than $600 \mathrm{~mm}$ ) implying a low chord slenderness $\gamma=\frac{D}{2 T}$ value, and the presence of a constructional gap inducing an eccentricity.

The fatigue strength of a tubular structure depends on the absolute and relative size of its members (size effect), on the loading case, on the initial crack-like imperfections, and on the welding residual stress fields.

In tubular joints, the complexity of the stress field has led to the use of a hot-spot stress concept [4] for characterizing the stress

\footnotetext{
* Corresponding author. Tel.: +41 2169324 25; fax: +41 216932868 .

E-mail addresses: claire.acevedo@a3.epfl.ch (C. Acevedo), alain.nussbaumer@ epfl.ch (A. Nussbaumer).
}

field at potential fatigue crack locations (hot-spot locations). Hotspot stress considers the effects of joint geometry and the type of load (stress concentration effect). It is a useful tool even though the determination of stresses using the hot-spot concept does not completely capture the size effect on fatigue resistance without a correction [2].

Due to the existence of initial imperfections in welded joints, it has been shown [5] that stable crack growth dominates the total fatigue life. Since welding imperfections, typically, of $0.1-0.2 \mathrm{~mm}$ depth are present in the vicinity of the weld toe [6,7], they act as crack initiators, meaning that there is almost no crack initiation phase in the fatigue life. Thus, the crack may start to propagate under the first load cycles.

Some design rules and studies are available to estimate the size effect $[8,2]$, the applied stress concentration due to traffic loads [3,1] and welding imperfections. However, three-dimensional residual stresses in tubular K-joints as well as their influence on fatigue crack propagation remain unknown.

This paper is not devoted to residual stress measurements in itself. It will be based on previous investigations conducted by the authors and presented in Section 2. The objective of the work presented herein is to evaluate the influence of tensile residual stresses on the fatigue crack development and the fatigue strength using large-scale tests.

The chosen strategy to separate the residual stress effect from the total internal stress effect is to focus on the behavior of details loaded in compression where cracks can only grow under the presence of high tensile residual stresses, and then compare it with the behavior of details loaded in tension. 


\author{
Nomenclature \\ D $\quad$ outside chord diameter ('sup': upper chord, 'inf': lower \\ chord) \\ $T \quad$ chord wall thickness \\ d outside brace diameter \\ $t \quad$ brace wall thickness \\ $e \quad$ eccentricity (positive here) \\ $g$ gap distance \\ $L_{c h} \quad$ chord length between two nodes \\ $\gamma_{\mathrm{Mf}} \quad$ partial safety factor for fatigue strength \\ hot-spot 1 fatigue crack location situated at the weld crown toe \\ on the tension brace \\ hot-spot 1c fatigue crack location situated at the weld crown toe \\ on the tension brace \\ Sx-Jy-z hot spot labeling: Specimen number $\mathbf{x}$ - Joint number \\ $\mathbf{y}$ - Hot-spot number $\mathbf{z}$ ( 1 or $1 \mathrm{c})$
}

$\alpha=\frac{2 L_{c h}}{D}$
$\beta=\frac{d}{D}$
$\gamma=\frac{D}{2 T}$
$\tau=\frac{t}{T}$
$\theta$
$\zeta=\frac{g}{D}$
$2 c$
$a$
$\Phi$
$N_{3}$
$N_{4}$
$K$

chord length slenderness

diameters ratio

chord slenderness

wall thickness ratio

brace angle

normalized gap parameter

crack length

crack depth at the deepest point

starting crack angle

number of cycles at through thickness cracking

number of cycles at complete loss of joint strength

stress intensity factor
In the CIDECT design guide for tubular welded joints under fatigue loadings [1], K-joint details loaded in compression are not considered to cause fatigue failure ('it is presumed that only braces which have some parts of their load range in tension will be liable to cause fatigue failure'). This raises the question as to the definition of 'fatigue failure'.

The definition of fatigue failure, i.e. crack size considered at failure, is not clear and not consistent between codes. In Eurocode 3 Part 1-9 [9] and CIDECT, our interpretation is that it is implicitly taken as a crack detectable by visual examination. In the IIW recommendations [4], the failure criterion for large components is defined as 'the observation of a larger or through-wall crack'. The failure criterion is also implicitly taken into account through the partial safety factor for strength $\gamma_{\mathrm{Mf}}$. In Eurocode 3 Part 1-9, 'crack-arresting details', such as the details loaded in compression, or other local failures which do not imply the failure of the structure are calculated with the damage tolerant method. This method uses a lower partial strength factor than the safe life method where formation of cracks could 'rapidly lead to failure of the structural element or structure'.

In this study, for comparison, both half and through-thickness cracking will be used as the failure criterion. The fatigue strength $S-N$ curves (stress $S$ range versus number of cycles $N$ ) will be analyzed for each criterion.

Experimental investigations are performed on large-scale tubular truss beams under constant amplitude loading. The experimental method is to monitor the fatigue development using the alternating current potential drop method, and to measure strains in order to obtain the $S-N$ fatigue results. Based on the comparison of the $S-N$ fatigue results and the corresponding $S-N$ design curves given in the codes, considerations will be conducted to assess the most appropriate fatigue design curve for bridge $\mathrm{K}$-joints with low chord slenderness $\gamma$ values.

\section{Residual stress measurements}

In a previous experimental study [10,11], measurements by neutron-diffraction on several K-joint samples were conducted by the authors. Results show that residual stress magnitude reaches the yield strength of S355 steel at the weld toe. At and near the surface, the largest tensile residual stress values are critically oriented transversely, i.e. perpendicularly to the weld direction, which is also the orientation of externally applied stresses. Fig. 1 shows the distribution of transverse residual stresses from the weld toe (at hot-spot 1 or hot-spot 1c see Fig. 2) and through the depth. This finding leads to a drastically different residual stress orientation than found in the literature for pipe and pressure vessel tubes [12,13]. For Y-, T-, pipe-to-plate and T-butt joints, the dominant residual stresses are parallel to the weld direction. The geometry of the K-joint creates high tensile residual stresses (from welding) in the gap region, which tend to open cracks and increase the fatigue crack propagation.

In codes, the influence of residual stresses on fatigue life are considered in different ways. In IIW recommendations, Eurocode 3 Part 1-9 and CIDECT, the $S-N$ curves include the effect of high residual stresses. The IIW and Eurocode 3 Part 1-9 codes recommend to use the fatigue $S-N$ curve category 100 (hot-spot stress method) for full penetration welds carrying loads. However, they do not provide specific curves for K-joints. K-joint fatigue curves are only given in the CIDECT guide which recommends to use another fatigue $S-N$ curve, namely category 114 .

\section{Fatigue tests}

Performing fatigue tests on large scale specimens ensured to combine complex loading with the presence of welding imperfections and residual stress field that occur in real bridge structures. To conduct fatigue tests, large scale truss beams are preferred to isolated $\mathrm{K}$-joints because they allow for combining, in a single specimen, details loaded under different multi-axial stress fields either in tension or in compression. The size of the specimen tubes represents approximately $1 / 2-2 / 3$ of the size of a real truss bridge section. Hence, joints are manufactured and welded in the same conditions as bridge joints ensuring to induce similar welding imperfections and residual stress distribution. As shown in Table 1, most of joint geometrical parameters are within the range of currently built bridges.

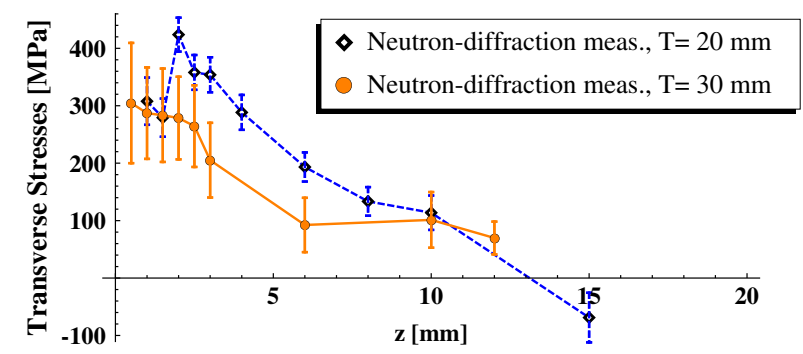

Fig. 1. Transverse residual stress values and error bars obtained by neutrondiffraction as a function of the depth $z$ along a vertical line underneath the weld toe. 


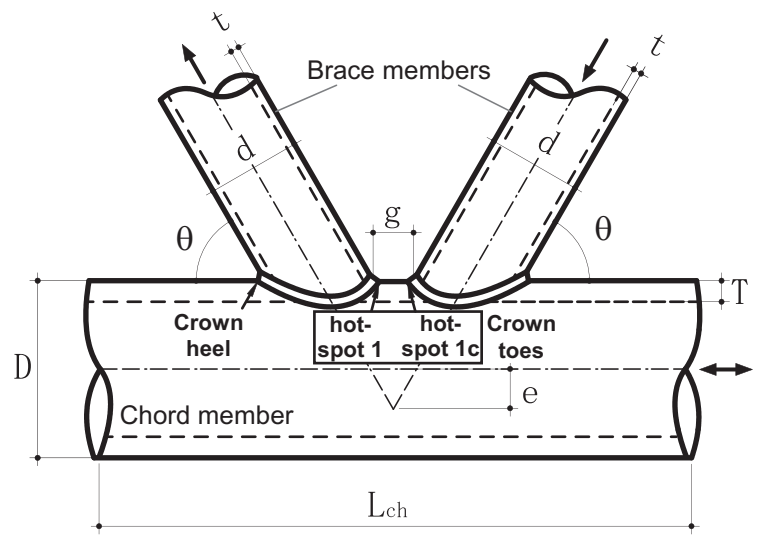

Fig. 2. Main dimensions of K-joints. Hot-spot 1 and hot-spot $1 \mathrm{c}$ positions are defined by the loading in the brace.

The choice of geometrical dimensions and geometrical parameters is driven by the idea of finding a parameter which could influence the residual stress value for a given depth. In welded structures made of plates and tubes, the proposed residual stress distribution is, most of the time, expressed as a function of $b / T$ where $b$ is the depth below the surface and $T$ is the plate or tube wall thickness $[16,12,13]$. Changing the wall thickness $T$ of specimens may result in a different residual stress distribution and then a different combination with applied stresses.

\subsection{Material and specimen manufacturing}

The steel grade chosen for the specimens is a S355J2H, according to EN 10210-1 (hot finished structural hollow sections of nonalloy and fine grain steels). The designation $\mathrm{S} 355 \mathrm{~J} 2 \mathrm{H}$ is used for a steel (S) with a minimum yield stress value of $355 \mathrm{MPa}$ (355) for a nominal thickness $t \leqslant 16 \mathrm{~mm}(\geqslant 345 \mathrm{MPa}$ for a nominal thickness $16 \mathrm{~mm}<t \leqslant 40 \mathrm{~mm}$ ) and a minimum toughness of $27 \mathrm{~J}$ at $-20^{\circ} \mathrm{C}(\mathrm{J} 2)$. In this case, it is furthermore a tubular hollow section (H).

The fully penetrated weld is made using the flux cored arc welding process with active gas. A sequence of seven weld passes is performed, starting from the crown heel and traveling to the crown toe in the gap region (see Fig. 2).

\subsection{Description of specimens and test series}

Two large scale tubular truss beams S6 and S7 $(8.6 \mathrm{~m}$ long and $1.8 \mathrm{~m}$ high) are subjected to high cycle fatigue. Fig. 3 depicts main dimensions and the circular hollow sections (CHS) chosen for truss girders. As shown in Table 1, specimens S6 and S7 are geometrically identical to each other except for the thickness $T$ of their upper and lower chord (respectively $20 \mathrm{~mm}$ and $30 \mathrm{~mm}$ for $\mathrm{S} 6$, $30 \mathrm{~mm}$ and $20 \mathrm{~mm}$ for S7).

Joints located at support positions and at the actuator position are post-weld treated by needle-peening in order to prevent early cracking. The rest of the joints are left as-welded, meaning that a total of six joints J3N, J3S, J1, J2 (on the chord loaded in tension) and $\mathrm{J} 5 \mathrm{~N}, \mathrm{~J} 5 \mathrm{~S}$ (on the chord loaded in compression) are likely to crack within a reasonable amount of testing time.

Four series S1, S2, S3 and S5 using similar specimens with different chord and brace CHS sections (Table 1) were tested at ICOM's laboratory by $[14,15]$. However, series S1-S3 were only devoted to joints welded onto the tension chord (lower chord).

\subsection{Test setup and test equipment}

The static testing system consists of a simple beam standing on concrete blocks located under the extremity of its upper chord. A cyclic concentrated load is applied at the center of the upper chord with a constant load range of $\Delta Q=549 \mathrm{kN}$ (minimum load $Q_{\min }=61 \mathrm{kN}$, maximum load $Q_{\max }=610 \mathrm{kN}$ ) and a load ratio $R=\frac{Q_{\min }}{Q_{\max }}=0.1$. This load range is chosen to be identical to previously tested series $\mathrm{S} 5$. Chord nominal stress range and load ratio $R$ are the same for series $S 3(\Delta Q=396 \mathrm{kN})$, series $\mathrm{S} 5$ and joints with a thickness $T$ of $20 \mathrm{~mm}$ in series S6 and S7. The cyclic fatigue load $Q$ is applied (load control) until the first crack reached the full thickness (corresponding the number of cycles to through-thickness cracking, defined as $N_{3}[17]$ ).

The two specimens are equipped and monitored with several experimental means:

- Uni-axial strain gauges and displacement transducer.

- Penetrant and magnetic inspection techniques to detect the first surface crack.

- Ink and beach marking to mark the crack shape after a given number of cycles.

- Crack opening at the end of testing.

Table 1

Nominal dimensions and geometrical parameters for specimens series S1-S7 tested under fatigue loading (S1-S4 from [14], S5 from [15], S6 and S7 highlighted in gray from the current study) and for real bridges.

\begin{tabular}{|c|c|c|c|c|c|c|c|c|c|c|}
\hline \multicolumn{2}{|c|}{ Series/bridge ecc. } & \multicolumn{4}{|c|}{ Nominal dimensions $(\mathrm{mm})$} & \multicolumn{5}{|c|}{ Geometrical parameters } \\
\hline & \multirow[b]{2}{*}{$e$} & \multirow{2}{*}{$\begin{array}{l}\text { Gap } \\
\mathrm{g} \\
\end{array}$} & \multirow{2}{*}{$\begin{array}{l}\text { Chord } \\
D_{\text {sup }} \times T_{\text {sup }}\end{array}$} & \multirow{2}{*}{$\begin{array}{l}\text { Chord } \\
D_{i n f} \times T_{i n f}\end{array}$} & \multirow{2}{*}{$\begin{array}{l}\text { Brace } \\
\mathrm{d} \times \mathrm{t}\end{array}$} & \multirow{2}{*}{$\begin{array}{l}\alpha \\
\left(\frac{2 L}{D}\right) \\
\end{array}$} & \multirow{2}{*}{$\begin{array}{l}\beta \\
\left(\frac{d}{D}\right) \\
\end{array}$} & \multirow{2}{*}{$\frac{\gamma_{\text {sup }} / \gamma_{\text {inf }}}{\left(\frac{D}{2 T}\right)}$} & \multirow{2}{*}{$\begin{array}{l}\tau_{\text {sup }} / \tau_{\text {inf }} \\
\left(\frac{t}{T}\right) \\
\end{array}$} & \multirow{2}{*}{$\frac{\theta}{\left(^{\circ}\right)}$} \\
\hline & & & & & & & & & & \\
\hline $\mathrm{S} 1$ & $20-28$ & $20-29$ & I-beam & $273 \times 20$ & $139.7 \times 12.5$ & 15.4 & 0.51 & /6.83 & /0.63 & 60 \\
\hline $\mathrm{S} 2$ & $50-55$ & $54-60$ & I-beam & $273 \times 20$ & $139.7 \times 12.5$ & 15.4 & 0.51 & /6.83 & /0.63 & 60 \\
\hline S3 & $28-39$ & $31-44$ & I-beam & $168.3 \times 12.5$ & $88.9 \times 8$ & 25.0 & 0.53 & /6.73 & /0.64 & 60 \\
\hline S4 & \multicolumn{10}{|c|}{ Geometrically identical to S1 and S2, but all joints were post-weld treated } \\
\hline S5 & 22 & 20 & $168.3 \times 20$ & $168.3 \times 20$ & $88.9 \times 8$ & 25.0 & 0.53 & $4.2 / 4.2$ & $0.4 / 0.4$ & 60 \\
\hline S6 & $32-39$ & $32-39$ & $168.3 \times 20$ & $168.3 \times 30$ & $88.9 \times 8$ & 25.0 & 0.53 & $4.2 / 2.8$ & $0.4 / 0.27$ & 60 \\
\hline S7 & $34-38$ & $34-38$ & $168.3 \times 30$ & $168.3 \times 20$ & $88.9 \times 8$ & 25.0 & 0.53 & $2.8 / 4.2$ & $0.27 / 0.4$ & 60 \\
\hline \multicolumn{4}{|c|}{ Antrenas France 94} & $1200 \times 32$ & $508 \times 16$ & & 0.42 & /18.75 & 10.5 & \\
\hline \multicolumn{3}{|c|}{ Aarwangen Switz. 97} & $406 \times 36-50$ & $406 \times 36-50$ & $194 \times 24-28$ & 12.4 & 0.48 & $4.1-5.6$ & $0.5-0.8$ & 45 \\
\hline \multicolumn{3}{|c|}{ Lully Switzerland 97} & $508 \times 25-50$ & $508 \times 25-50$ & $267 \times 11-25$ & 14.0 & 0.53 & $5-10.2$ & $0.2-1$ & 60 \\
\hline \multicolumn{3}{|c|}{ Nesenbacht. Germ. 99} & $324 \times 16-80$ & $324 \times 16-80$ & $194 \times 10-60$ & 19.5 & 0.60 & $2-10.1$ & $0.6-0.8$ & 46 \\
\hline \multicolumn{3}{|c|}{ Dättwil Switz. 2001} & $508 \times 50$ & $508 \times 50$ & $267 \times 11-25$ & 14.6 & 0.53 & 5.1 & $0.2-0.5$ & 60 \\
\hline \multicolumn{3}{|c|}{ Korntal Germ. 2002} & $457 \times 45-65$ & $457 \times 45-65$ & $267 \times 28-45$ & 16 & 0.58 & $3.5-5.1$ & $0.6-0.7$ & 60 \\
\hline \multicolumn{3}{|c|}{ St-Kilian Germ. 2004} & I-beam & $610 \times 50-60$ & $298.5 \times 55-60$ & $\sim 12.5$ & 0.49 & |5.1-6.1 & $1-1.1$ & $\sim 60$ \\
\hline \multicolumn{3}{|c|}{ Bridge values } & $300-700 \times 10-80$ & $300-700 \times 10-80$ & $100-300 \times 10-60$ & $10-20$ & $0.4-0.65$ & $3-12$ & $0.2-1.2$ & $40-60$ \\
\hline
\end{tabular}




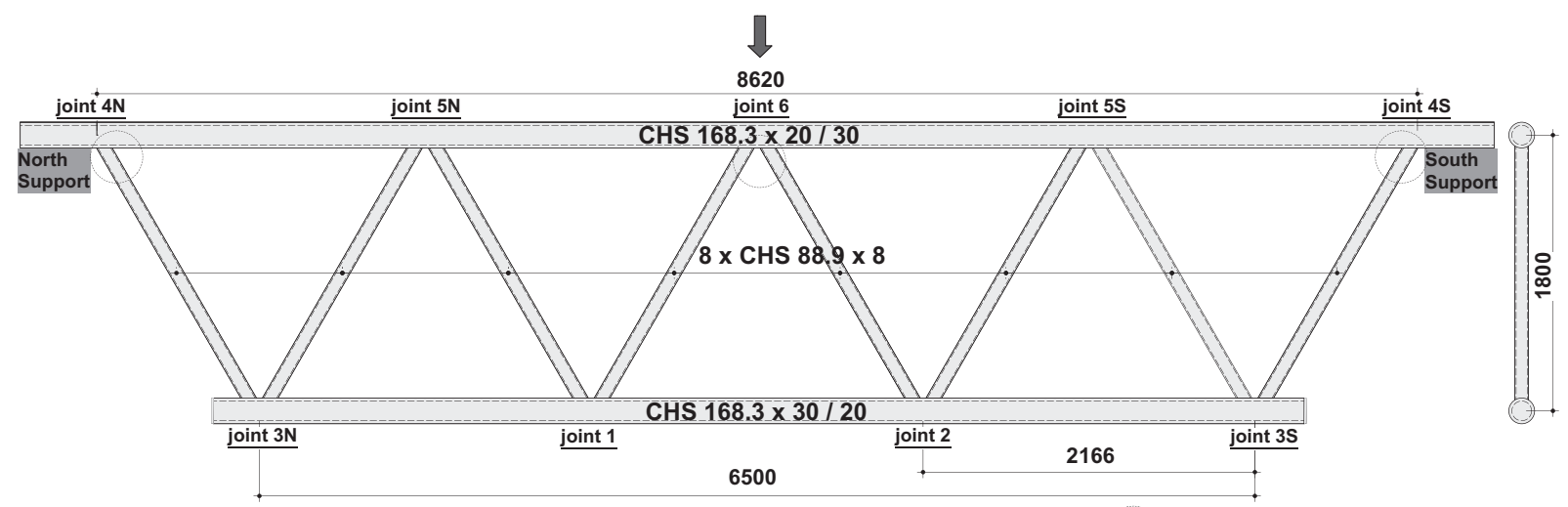

$=$ post-weld treated joints (needle-peening)

Fig. 3. Overview of truss beam specimens $\mathrm{S} 6$ and $\mathrm{S} 7$ with main dimensions (in $\mathrm{mm}$ ) and joint identification.

- Alternating Current Potential Drop (ACPD) is used to follow the crack depth evolution during a fatigue test [18]. This nondestructive technique is based on the property of alternating current to flow on a thin layer close to the surface (skin effect) of electrical conductive materials. Therefore, when the skin current encounters a crack, it goes down and up along crack faces. As a consequence, it is possible to calculate the crack depth of any surface crack occurring between probes based on ACPD measurements [15]. In Fig. 4, the crack depth d measured at the probe position is shown. Note that this is not the crack depth at the deepest point along the weld toe, $a$. The error on $d$ is estimated to be less than $25 \%$ for a small crack size $(a=1 \mathrm{~mm})$ and negligeable once the crack size is over $7 \mathrm{~mm}$ depth.

The crack propagation rate is estimated as $\Delta d / \Delta N$ and the experimental stress intensity factor $\Delta K$ is deduced from the Paris law:

$$
\Delta K=\left(\frac{1}{C} \frac{\Delta d}{\Delta N}\right)^{\frac{1}{m}}
$$

where $\mathrm{C}=2 \times 10^{-13}(\mathrm{~mm} /$ cycle $)\left(\mathrm{N} / \mathrm{mm}^{-3 / 2}\right)^{\mathrm{m}}[19]$ and $m=3$ [5] for ferrite-pearlite steels.

\subsection{Test results}

\subsubsection{Hot-spot stress range evaluation}

Based on extrapolated strain measurements at the weld toe, axis stresses can be calculated using the 2D Hooke's law. Assuming that strain in the axial member direction $x$ is dominating compared to strains in the other direction $\left(\varepsilon_{x} \gg \varepsilon_{y}\right)$ and that
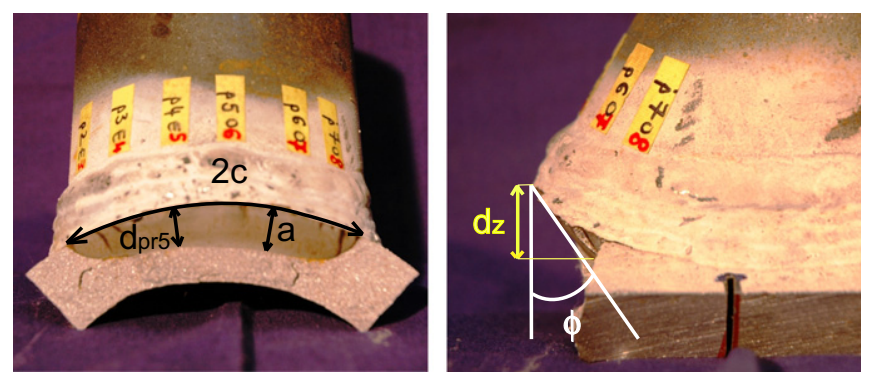

Fig. 4. Presentation of a fatigue crack, once the crack is opened after the test. The crack depth $d$ was measured during the test using the ACPD method, at probe position 5 in this case. $d_{z}$ is the projection of $\mathrm{d}$ on the vertical axis. the Poisson's ratio $v=0.3$ for steel, the equation can be reduced to $\sigma_{x}=1.1 \mathrm{E} \varepsilon_{x}$. Investigations conducted [2] on a large database of joint hot-spot strain results have revealed that a ratio of 1.17 $\left(\sigma_{x}=1.17 \mathrm{E} \varepsilon_{x}\right)$ is more appropriate. This value is adopted for stress calculation.

By simply multiplying nominal stresses by the corresponding stress concentration factors SCFs, stresses at the weld toe called hot-spot stresses are calculated. Since stresses are elastic, the total hot-spot stress range $\Delta \sigma_{h s, i}$ or $S_{R, h s, i}$ is the superposition of hot-spot stress range under each load case [1] (axial brace force: ax-br, moment in brace: ipb-br, axial chord force: ax-ch, moment in chord: ipb-ch) at the joint location i:

$$
\begin{aligned}
\Delta \sigma_{h s, i}= & \Delta \sigma_{a x-b r} \cdot \mathrm{SCF}_{i, a x-b r}+\Delta \sigma_{i p b-b r} \cdot \mathrm{SCF}_{i, i p b-b r}+\Delta \sigma_{a x-c h} \\
& \cdot \mathrm{SCF}_{i, a x-c h}+\Delta \sigma_{i p b-c h} \cdot \mathrm{SCF}_{i, i p b-c h} \\
= & \Delta \sigma_{\text {tot nom }} \cdot \mathrm{SCF}_{t o t, i}
\end{aligned}
$$

SCF tables for the four load cases (ax-br, ipb-br, ax-ch, ipb-ch) were determined by Schumacher [17] for similar K-joints. The SCF study from Schumacher has the advantage of being specifically devoted to bridge K-joints, characterized by a low $\gamma$ value $(\gamma<12)$ and the presence of a gap (or an eccentricity). SCF factors were only based on experimental results obtained in joints J1 and J2. This experimental research has shown that SCF values given in the $\mathrm{CI}-$ DECT design guide overestimate the SCF measured values.

SCF factors were calculated at the most critical locations: hotspot 1 and 1c (Fig. 2).

Hot-spot stresses obtained by applying Eq. 2 are presented in Table 2 . It is seen that calculated hot-spot stresses $\Delta \sigma_{\mathrm{hs}, \mathrm{i}}$ are lower than nominal stresses $\Delta \sigma_{\text {tot nom }}$ and this trend seems to be linked to the chord wall thickness. It can be argued that when the stress deviation occurs between a thin brace wall and a thick chord wall, there is an effect of 'low pressure stress area'. Stress concentrations drop in the area of the weld toe by analogy with a fluid flow that abruptly changes direction. This trend is also confirmed by results of test series S5 as well as by finite element analyses carried out to determine hot-spot stresses in joints.

Note that the load ratio $R=0.1$ corresponds to a stress ratio $R=\sigma_{\min } / \sigma_{\max }=0.1$ in details loaded in tension (hot-spot 1 in Table 2) and a stress ratio $R=\sigma_{\min } / \sigma_{\max }=10$ in details loaded in compression (hot-spot $1 \mathrm{c}$ in Table 2 ). These loadings are closed to zero-tension loading for $R=0.1$ and zero-compression loading for $R=10$.

Among these applied loadings, details can undergo a fully-tensile loading (brace and chord in tension), a part-tensile/-compressive loading (brace or chord in tension) or a fully-compressive loading (brace and chord in compression). 
Table 2

Hot-spot stress calculations for each joint at location hot-spot 1 for the crown toe on the tension side and hot-spot 1c for the crown toe on the compression side. Joints highlighted in italics are respectively fully-tensile loaded for hot-spot 1 and fully-compressive loaded for hot-spot 1c. Bold values are the Stress Concentration Factors (SCF) and the hot-spot stress ranges $\left(\Delta \sigma_{h s}\right)$.

\begin{tabular}{|c|c|c|c|c|c|c|}
\hline \multirow[t]{2}{*}{ Joint } & \multicolumn{3}{|l|}{ Hot-spot 1} & \multicolumn{3}{|l|}{ Hot-spot 1c } \\
\hline & $\Delta \sigma_{\text {tot nom }}(\mathrm{MPa})$ & $\mathrm{SCF}_{\text {tot }, 1, \text { cor }}$ & $\Delta \sigma_{h s, 1}(\mathrm{MPa})$ & $\Delta \sigma_{\text {tot nom }}(\mathrm{MPa})$ & $\mathrm{SCF}_{\text {tot }, 1 \mathrm{c}, \mathrm{cor}}$ & $\Delta \sigma_{h s, 1 \mathrm{c}}(\mathrm{MPa})$ \\
\hline S6-J3S & 251 & 0.55 & 139 & 247 & 0.55 & 135 \\
\hline S6-J3N & 251 & 0.55 & 139 & 245 & 0.54 & 133 \\
\hline S6-J1 & 242 & 0.61 & 148 & 144 & 0.53 & 76 \\
\hline S6-J2 & 241 & 0.62 & 148 & 145 & 0.53 & 77 \\
\hline S6-J5S & 177 & 0.78 & 139 & 310 & 0.91 & 284 \\
\hline S6-J5N & 180 & 0.78 & 141 & 310 & 0.91 & 284 \\
\hline S7-J3S & 260 & 0.87 & 225 & 241 & 0.85 & 205 \\
\hline S7-J3N & 260 & 0.87 & 225 & 241 & 0.85 & 205 \\
\hline S7-J1 & 262 & 0.92 & 240 & 133 & 0.88 & 117 \\
\hline S7-J2 & 262 & 0.92 & 240 & 133 & 0.89 & 118 \\
\hline S7-J5S & 199 & 0.45 & 89 & 309 & 0.62 & 192 \\
\hline S7-J5N & 198 & 0.44 & 88 & 309 & 0.62 & 192 \\
\hline
\end{tabular}

Table 3

Crack shapes of specimen S6 as a function of cycle numbers $\left(N_{3}\right.$ is the number of cycles to through-thickness cracking). Symbols ${ }^{\dagger}$ and ${ }^{\star}$ mean respectively 'not marked' and 'beach-mark not identifiable'. The critical crack is highlighted in italics.

\begin{tabular}{|c|c|c|c|c|c|c|c|c|c|c|c|}
\hline \multirow[t]{2}{*}{ Joint no. (S6) } & & \multicolumn{3}{|c|}{ Ink mark 90,000 cyc. } & \multicolumn{3}{|c|}{ Beach mark 140,000 cyc. } & \multicolumn{4}{|c|}{ Open. $N_{3}=242,000$ сус. } \\
\hline & & $a(\mathrm{~mm})$ & $2 c(\mathrm{~mm})$ & $a / c$ & $a(\mathrm{~mm})$ & $2 c(\mathrm{~mm})$ & $a / c$ & $a(\mathrm{~mm})$ & $2 c(\mathrm{~mm})$ & $a / c$ & $\Phi\left({ }^{\circ}\right)$ \\
\hline S6-J3S & Tensile & 8 & 52 & 0.31 & 16 & 80 & 0.4 & 25 & 240 & 0.21 & 48 \\
\hline$T=30 \mathrm{~mm}$ & Compress. & + & & & $\ddagger$ & & & 5 & 40 & 0.25 & 50 \\
\hline S6-J3N & Tensile & 7 & 46 & 0.3 & 15 & 75 & 0.4 & 25 & 125 & 0.4 & 40 \\
\hline$T=30 \mathrm{~mm}$ & Compress. & $\dagger$ & & & $\ddagger$ & & & 11 & 60 & 0.37 & 40 \\
\hline S6-J1 & Tensile & 4 & 28 & 0.29 & 8 & 42 & 0.38 & 19 & 100 & 0.38 & 40 \\
\hline$T=30 \mathrm{~mm}$ & Compress. & + & & & $\ddagger$ & & & 2 & 10 & 0.4 & 35 \\
\hline S6-J2 & Tensile & 3 & 48 & 0.13 & 9 & 60 & 0.3 & 20 & 110 & 0.36 & 40 \\
\hline$T=30 \mathrm{~mm}$ & Compress. & + & & & $\ddagger$ & & & 4 & 27 & 0.3 & 35 \\
\hline S6-J5S & Tensile & + & & & $\ddagger$ & & & 11 & 60 & 0.37 & 30 \\
\hline$T=20 \mathrm{~mm}$ & Compress. & $\dagger$ & & & $\ddagger$ & & & 11 & 85 & 0.26 & 40 \\
\hline S6-J5N & Tensile & + & & & $\ddagger$ & & & 12 & 70 & 0.34 & 40 \\
\hline$T=20 \mathrm{~mm}$ & Compress. & $\dagger$ & & & $\ddagger$ & & & 16 & 100 & 0.32 & 30 \\
\hline
\end{tabular}

Table 4

Crack shapes of specimen S7 as a function of cycle numbers ( $N_{3}$ is the number of cycles to through-thickness cracking). Symbol ${ }^{\dagger}$ means 'not marked'. The critical crack is highlighted in italics.

\begin{tabular}{|c|c|c|c|c|c|c|c|c|c|}
\hline \multirow[t]{2}{*}{ Joint no. (S7) } & & \multirow{2}{*}{$\begin{array}{l}\text { Insp. } 50,000 \text { cyc. } \\
2 \mathrm{c}(\mathrm{mm})\end{array}$} & \multicolumn{3}{|c|}{ Ink mark 90,000 сус. } & \multicolumn{4}{|c|}{ Open. at $N_{3}=111,000$ сус. } \\
\hline & & & $\mathrm{a}(\mathrm{mm})$ & $2 \mathrm{c}(\mathrm{mm})$ & $a / c$ & $\mathrm{a}(\mathrm{mm})$ & $2 c(\mathrm{~mm})$ & $a / c$ & $\Phi\left({ }^{\circ}\right)$ \\
\hline S7-J3S & Tensile & 45 & 20 & 100 & 0.4 & 35 & 225 & 0.31 & 48 \\
\hline$T=20 \mathrm{~mm}$ & Compress. & & $\dagger$ & & & 1 & 20 & 0.1 & \\
\hline S7-J3N & Tensile & 35 & 18 & 115 & 0.31 & 27 & 150 & 0.36 & 38 \\
\hline$T=20 \mathrm{~mm}$ & Compress. & & $\dagger$ & & & 1 & 13 & 0.15 & \\
\hline S7-J1 & Tensile & & $\dagger$ & & & 12 & 85 & 0.28 & 38 \\
\hline$T=20 \mathrm{~mm}$ & Compress. & & $\dagger$ & & & 2 & 22 & 0.18 & 35 \\
\hline S7-J2 & Tensile & 20 & 10 & 85 & 0.24 & 16 & 90 & 0.36 & 40 \\
\hline$T=20 \mathrm{~mm}$ & Compress. & & $\dagger$ & & & 3 & 24 & 0.25 & 45 \\
\hline S7-J5S & Tensile & & $\dagger$ & & & 0.5 & 13 & 0.1 & \\
\hline$T=30 \mathrm{~mm}$ & Compress. & & $\dagger$ & & & 1 & 18 & 0.1 & \\
\hline S7-J5N & Tensile & & $\dagger$ & & & 1 & 17 & 0.12 & \\
\hline$T=30 \mathrm{~mm}$ & Compress. & & $\dagger$ & & & 5.5 & 35 & 0.31 & 40 \\
\hline
\end{tabular}

\subsubsection{Crack location}

For both specimens, cracks propagate for all non-treated joints (joints J1, J2, J3N, J3S, J5N and J5S). Cracks grow in the chord wall and along the weld toe whatever the sign of applied stresses, positive or negative. In total, twelve cracks per specimen are counted.

All these cracks occur at the weld toe in-between braces, at locations hot-spot 1 for the tensile brace side or hot-spot 1c for the compressive brace side. According to Tables 3 and 4, hot-spots where crack initiated were always locations of highest applied stresses and hot-spot stresses. In addition, other aspects such as local weld geometry, local imperfections, high hardness values and high tensile residual stresses tend to make these positions even more critical.
Cracks initiate in the heat affected zone HAZ because of contribution of stress concentration, metallurgical discontinuities and high numbers of dislocations in the HAZ microstructure. Then, the crack propagates in the base material BM. Apart from the first $2 \mathrm{~mm}$, the crack profile path is essentially within the BM.

\subsubsection{Through thickness cracking (defined at $N_{3}$ cycles)}

The first test on specimen S6 is stopped after 242,000 cycles, when a through crack occurs in joint S6-J3S-1. For the second test, the through crack is appeared sooner in joint S7-J3S-1 after only 111,000 cycles. At 50,000 cycles, first cracks in joints S7-J3S-1 and $57-\mathrm{J} 3 \mathrm{~N}-1$ are detected with dye penetrant whereas in 
specimen S6, no crack showed up for the same number of cycles (see Table 4).

The bigger cracks obtained at the end of fatigue tests are located at hot-spot 1 on the chord loaded in tension (S6-J3S-1, S6-J3N-1, S6-J2-1, S6-J1-1/S7-J3S-1, S7-J3N-1, S7-J2-1, S7-J1-1). Intermediate crack sizes are obtained at hot-spot $1 \mathrm{c}$ on the chord loaded in compression (S6-J5N-1c, S6-J5S-1c/S7-J5N-1c, S7-J5S-1c). Concerning the smallest cracks, the ranking of their size is different in specimens S6 and S7 and difficult to predict.

Therefore both critical cracks are situated in the joint at the extremity of the lower chord. However, the shape of their crack surface is completely different as shown in Fig. 5. Note that both joints are geometrically the same except for their wall chord thickness.

The crack that started from the brace weld toe of detail S6-J3S loaded in tension propagated following a curved path from the weld toe to the backing ring crown toe, passing underneath the brace wall and weld, whereas in detail S7-J3S the crack went directly through the $20 \mathrm{~mm}$ thickness of the chord after 111,000 cycles.

\subsection{4. $S_{\text {rhs }}-N$ curves}

Fatigue test results, including all series $\mathrm{S} 1-\mathrm{S} 7$, are reported in Fig. $6 \mathrm{a}$ in the form of logarithmical $S_{\text {rhs }}-N$ curves (or $\Delta \sigma_{\mathrm{R}, \mathrm{hs}}-N$ curves). The hot-spot stress range $\Delta \sigma_{\mathrm{R}, \mathrm{hs}}$ is taken at hot-spot 1 or hot-spot 1c. The hot-spot stress range values given in Table 2 are corrected, using the size effect correction determined by [2] for CI$\mathrm{DECT}$, in order to represent the fatigue strength of an equivalent $16 \mathrm{~mm}$ thick joint. Therefore, results can be compared between joints with different wall chord thicknesses. The number of cycles used in Fig. 6a refers to $N_{3, T / 2}$, the number of cycles to half-thickness cracking of the chord wall. Since cracks at hot-spot 1c usually do not attain the through-thickness, the choice of the half-thickness crack as 'failure' criterion is very important to compare results obtained in compression with others obtained in tension. At halfthickness, it is found from previous tests that the majority of the fatigue life $(60-80 \%$ of the number of cycles to through-thickness cracking) has usually been consumed. The number of cycles $N_{3, T / 2}$ are, for most of joints, interpolated and, for others, extrapolated
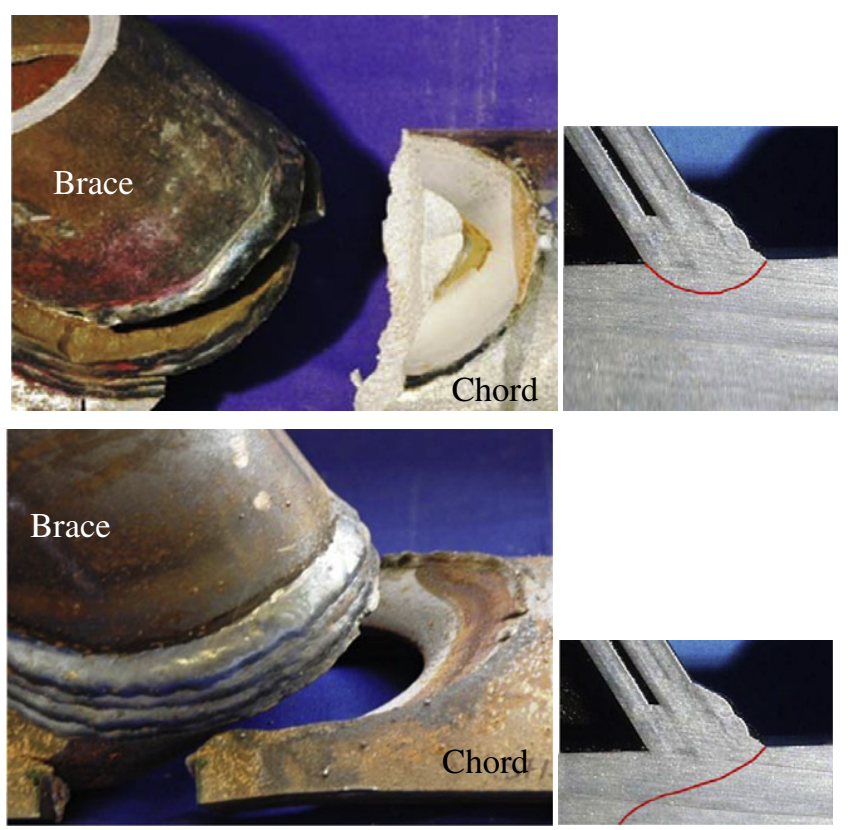

Fig. 5. Critical crack shape of joints S6-J3S $(T=30 \mathrm{~mm})$ on the top and S7-J3S $(T=20 \mathrm{~mm})$ on the bottom. based on the surface crack length $2 c$. This extrapolation is done for joints in which cracks almost reached the half-thickness criterion in order to have a uniform comparison basis.

Following IIW recommendations [4], a statistical analysis of results on fully-tensile loaded details is carried out. The mean $S-N$ curve is set up through a linear regression analysis with a constant slope of $m=3$ up to the constant amplitude fatigue limit, $N=5 \cdot 10^{6}$ cycles, and a constant slope of $m=5$ above the constant amplitude fatigue limit. Then, the characteristic curve is determined at 2.2 standard deviation (for 22 data points) below the mean value of $\log N$, thus given the reference value of fatigue strength $S_{\text {rhs }\left(2.10^{6}\right), 95 \%}$ defined as the $95 \%$ percentile with a confidence level of $75 \%$ for a two-sided interval. As shown in Fig. 6a, the obtained reference value at $N_{3, T / 2}$, also called the detail category, is 80 .

The same analysis is carried out with $S_{\text {rhs }}-N_{4}$ data (Fig. 6b) where $N_{4}$ is the number of cycles at which there is a complete loss of the joint strength [17]. The $N_{4}$ value is obtained by multiplying the number of cycles to through-thickness cracking, $N_{3}$, by 1.49 [2]. The resulting detail category is 103 which is inferior to the $S_{\mathrm{R}, \mathrm{hs}}-N$ design curves category 114 recommended by CIDECT for $T=16 \mathrm{~mm}$ [1]. A direct comparison is however difficult since the CIDECT and IIW guidelines $[1,20]$ does not strictly apply to the geometrical parameters (i.e. the SCF and hot-spot stress ranges cannot be computed using the guideline formulas). The SCF's computed by these guidelines overestimate the real SCF's for the geometrical parameters [14], and thus the $S-N$ curve 114 overestimates the fatigue life. The category 100 , depicted in Fig. $6 \mathrm{~b}$, is more reliable for the fatigue design of tubular joints with a $\gamma<12$.

In Fig. 6a, the detail categories 80 is drawn with the $S_{\mathrm{rhs}}-N$ results under fully-tensile loading used to obtain this curve category 80 . The $S_{\text {rhs }}-N$ results under fully compressive, part-tensile and part-compressive loadings are also added in this figure. It is seen that all these additional data fall on or above the $S-N$ curve category 80 , meaning that this curve is appropriate to estimate the fatigue strength of joints in tension and in compression. Note that the data points for details in compression (square symbols) are drawn with fully effective hot-spot stress range values. Knowing that tensile residual stress values are high on at least half of the wall chord thickness (see Fig. 1), it is assumed that the stress range is entirely effective. Therefore, the effective hot-spot stress range is taken as the hot-spot stress range $\Delta \sigma_{\text {eff,hs }}=\Delta \sigma_{\text {hs. }}$. If the hot-spot stress range is not considered as fully effective, the test points would fall below the $S-N$ curve category 80 implying that joints in compression have a lower fatigue strength than the rest of joints. This is not coherent. Only the fully effective model seems to be acceptable.

\section{Discussion}

\subsection{Crack development under fully-tensile loading}

The difference in the number of cycles to through-thickness cracking $\left(N_{3}\right)$ in joints S6-J3S- 1 and S7-J3S-1 indicates a difference in the crack propagation rate (Tables 3 and 4). It can be easily explained by the variation between the $\Delta \sigma_{h s, 1}$ of joints S6-J3S and S7J3S (hot-spot 1 in Table 2). Since the well-known Paris law [21] is used to estimate the crack propagation rate for a stable crack growth in fatigue, the propagation rate is a function of the hot-spot stress range to the power of $m=3$. Roughly, for a same final crack length, the propagation rate of joint S7-J3S-1 should be approximately 4 times higher (ratio $(225 / 139)^{3}$ ) than the one of joint S6J3S-1. Knowing that in reality $a_{f}=25 \mathrm{~mm}$ in joint S6-J3S-1 and $a_{f}=35 \mathrm{~mm}$ in joint S7-J3S-1, then the multiplier is adjusted to 23 times. This estimation is in good agreement with the resulting propagation rate. Therefore, the change in the crack propagation 


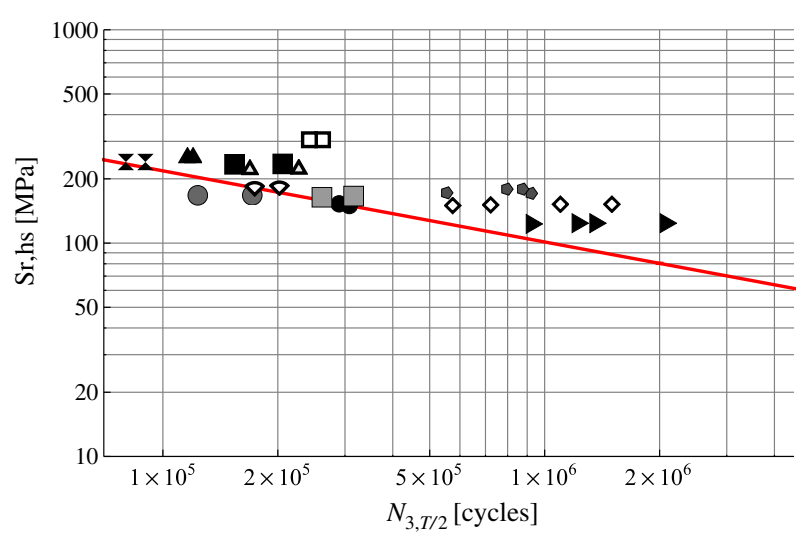

(a) $\mathrm{S}_{\mathrm{rhs}}-\mathrm{N}$ curve at half-thickness cracking

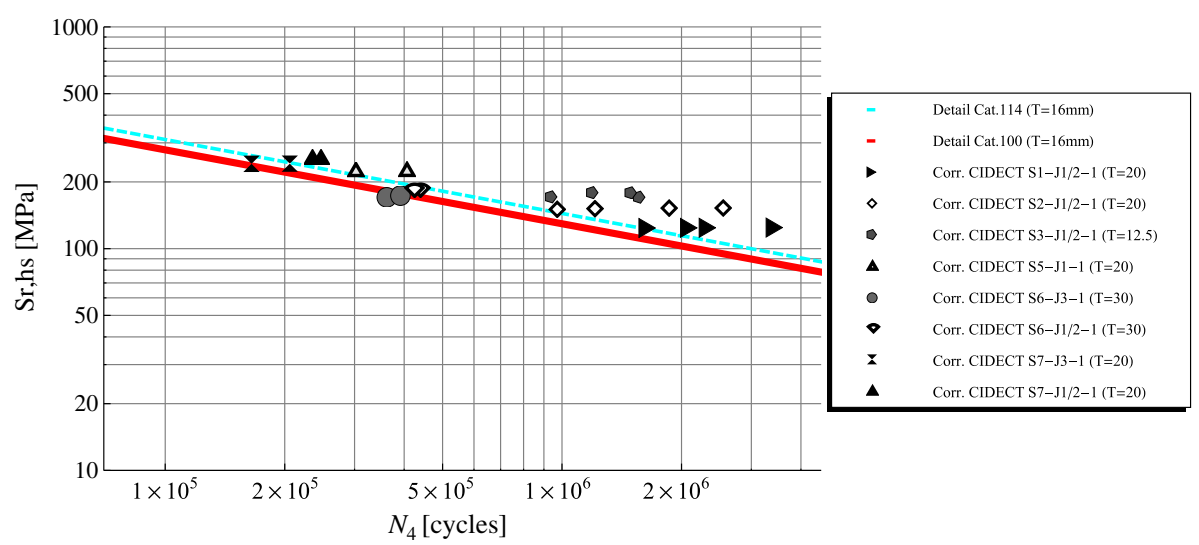

(b) $\mathrm{S}_{\text {rhs }}-\mathrm{N}$ curve for a complete loss of the joint strength cracking

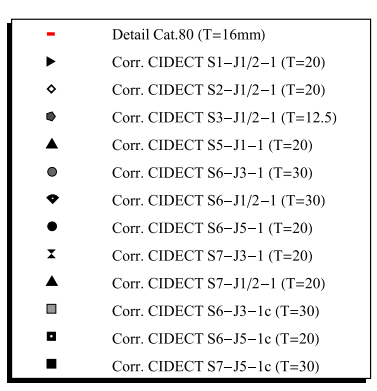

Corr. CIDECT S1-JI/2-1 (T=20)

Corr. CIDECT S2-J1/2-1 (T=20)

CIDECT S3-J1/2-1 (T=12.5)

Corr. CIDECT S5-J1-1 (T=20)

$1 / 2-1(\mathrm{~T}=30)$

Corr. CIDECT $57-\mathrm{J} 3-1(\mathrm{~T}=20)$

Fig. 6. Fatigue test results (hot-spot stress range values corrected to the equivalent $16 \mathrm{~mm}$ thickness) for series $\mathrm{S} 1-\mathrm{S} 7$ and detail categories 80 and 100.

rate between joints S6-J3S-1 and S7-J3S-1 can be entirely explained by the variation of the applied stress range.

The angled path followed by the crack varies between joints S6J3S-1 and S7-J3S-1 (see Fig. 5). This indicates that the direction of principal stresses is more affected by brace loads in joint S6-J3S-1 than in joint S7-J3S-1. Indeed, applied stress values in the $30 \mathrm{~mm}$ wall chord (S6-J3S) underneath the brace in compression are smaller than in the $20 \mathrm{~mm}$ wall chord (S7-J3S). Therefore, for approximately the same brace stresses, the proportion of brace stresses is higher in joint S6-J3S-1 explaining why the crack turns around the brace wall toe and do not cut across the chord wall. In joint S7-J3S-1, the crack turns toward the brace at mid-chord thickness, however chord stresses are high enough to change their direction and drive the crack path through the chord wall. Despite the fact that the applied stress range in joints $\mathrm{J} 1-1$ and $\mathrm{J} 2-1$ is higher, they are less critical than in joints J3S- 1 and J3N-1, stressing again the importance of the brace stress proportion.

Therefore, cracks occurring at hot-spot 1 under fully-tensile loading are driven by applied stresses. Their propagation rate is influenced by the applied stress range magnitude and their crack path seems to be strongly dependent on the applied stress range distribution and especially the proportion of brace stresses. In other words, the residual stress field does not affect the crack growth in details loaded in tension.

\subsection{Crack development under fully-compressive loading}

Previous conclusions are not applicable to cracks at hot-spot 1c (fully-compressive loading). For instance, it is seen in Fig. 7 representing the crack depth development followed using the ACPD

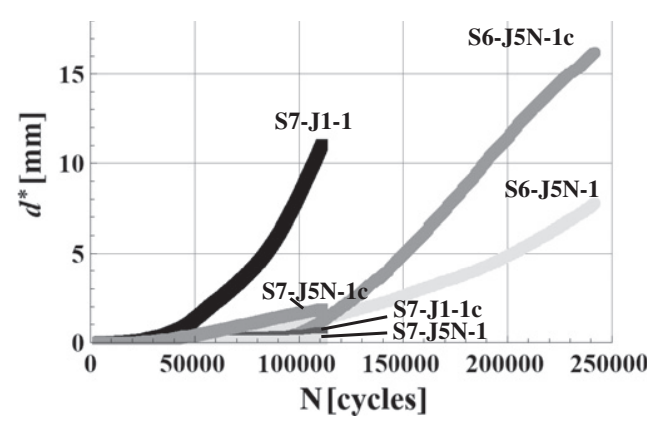

Fig. 7. Fatigue crack development in the monitored joints.

measurements that the crack propagation rate at hot-spot 1c is quite similar in joints S6-J5N-1C and S7-J5N-1c, whereas hot-spot stress magnitudes are different. In addition, the crack angle seems to be maintained through the thickness independently of applied stress distribution. Hence at hot-spot 1c the crack path is mainly influenced by the tensile residual stresses.

To understand how a crack can develop under fully-compressive fatigue loading, the experimental stress intensity factor SIF ranges are deduced and plotted from ACPD measurements as a function of the meaured crack depth (Eq. 1). Fig. 8 gives evidence that, under compressive and tensile applied stresses, the effective SIF range $\Delta K_{\text {eff }}$ is still positive explaining why cracks propagate even under compressive loads. The effective SIF range $\Delta K_{\text {eff }}$ is defined in Eq. 3 [22].

$\Delta K_{\text {eff }}=K_{\text {app }, \max }-K_{\text {op }}=K_{\text {app, } \max }+\left(K_{\text {res }}+K_{p l}\right) \leqslant \Delta K_{\text {app }}$ 


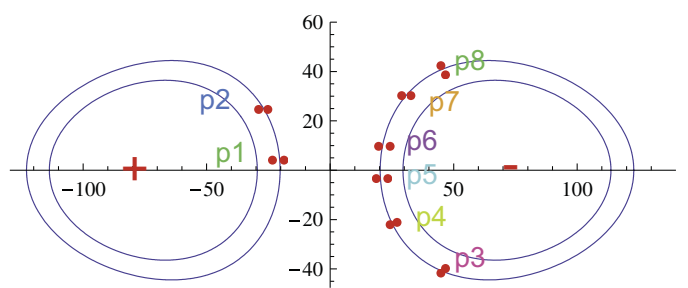

(a) Probe positions along the weld toe

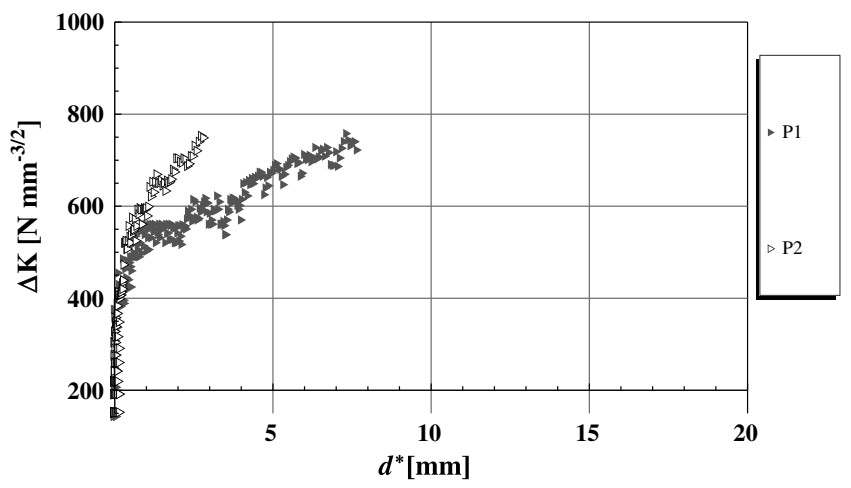

(b) Joint S6-J5N, tension brace side

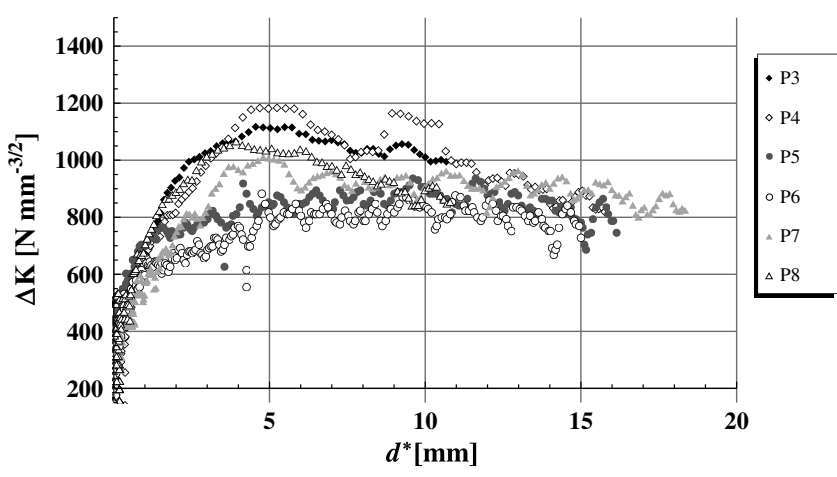

(c) Joint S6-J5N, compression brace side

Fig. 8. Stress intensity factor range in joint S6-J5N versus the crack depth $d^{*}$ measured at different probe position along the crack length (log-log scale).

In compression, the applied maximum and minimum SIFs, $K_{\text {app,max }}$ and $K_{\text {app,min }}$, are both negative for all crack depths. A positive effective SIF range $\Delta K_{\text {eff }}$ still occurs in compression because the SIF due to high tensile residual stresses, $K_{\text {res}}$, is positive. The SIF due to crack closure, $K_{\mathrm{pl}}$, is negative, however always lower in magnitude than $K_{\text {res }}$, resulting in a negative crack closure stress, $K_{\mathrm{op}}$. Since $K_{\mathrm{op}}$ is less than $K_{\mathrm{app} \text {,max }}$ for all crack depths, $\Delta K_{\mathrm{eff}}$ is positive, and thus the crack is able to propagate. Fig. 8 indicates that $\Delta K_{\text {eff }}$ remains positive at least to a depth of $15 \mathrm{~mm}$. Note that in details loaded in tension, the $\Delta \mathrm{K}$ is positive with or without presence of tensile residual stresses.

Tensile residual stresses play a significant role in crack propagation since they enable cracks to propagate at locations where applied compressive stresses are high.

\subsection{Crack development under party-tensile and party-compressive loading}

Crack propagation at hot-spot $1 \mathrm{c}$ on the chord loaded in tension (part-compressive loading) or hot-spot 1 on the chord loaded in compression (part-tensile loading) is more complex to explain. For instance, in comparing the crack in detail S6-J5N-1 (part-tensile loading) and the crack in detail S6-J3S-1 (full-tensile loading), cracks initiate and propagate with totally different rates despite the fact that both details have almost the same hot-spot stress range (see Table 3). It appears that, for the same hot-spot stress range, cracks grow slowly in details submitted to part-tensile loading.

The cracks in details S7-J3N-1c and S7-J3S-1c (part-compressive loading) are also compared to cracks in details S7-J5N-1c and S7J5S-1c (fully-compressive loading) presenting similar hot-spot stress range (see Table 4). Since cracks occur under compressive loading, it is clear that the crack development depends on the tensile residual stress field. It is seen that the critical crack occurs in fully-compressive loaded details even though cracks grow quite similarly in other details. It is worth noting that crack sizes are too small to draw a definite conclusion.

An explanation may be proposed for this phenomenon. For parttensile loading, the crack initiates in the surface at hot-spot 1 under tensile loading and grows in the depth of the wall chord thickness under more and more compressive loading. For partcompressive loading, the stress field on the crack path is reversed. In other words, the part-tensile or part- compressive loading is the transition between a tensile loading type and a compressive loading type, thus between two different fatigue crack behaviors. The maximum crack opening is shifted under tensile and compressive loading (under $Q_{\max }$ in tension, under $Q_{\min }$ in compression) involving a disturbance that probably slows down the crack propagation.

\subsection{Crack depth evolution}

The evolution of the crack growth is shown in Fig. 9. The crack propagation rate is given as a function of the measured crack depth. Fig. 9 shows different trends under tensile and compressive loadings.

Crack initiation and growth in joint S6-J5N first occurs from hot-spot 1c (S6-J5N-probe5 at 12,000-16,000 cycles, compression

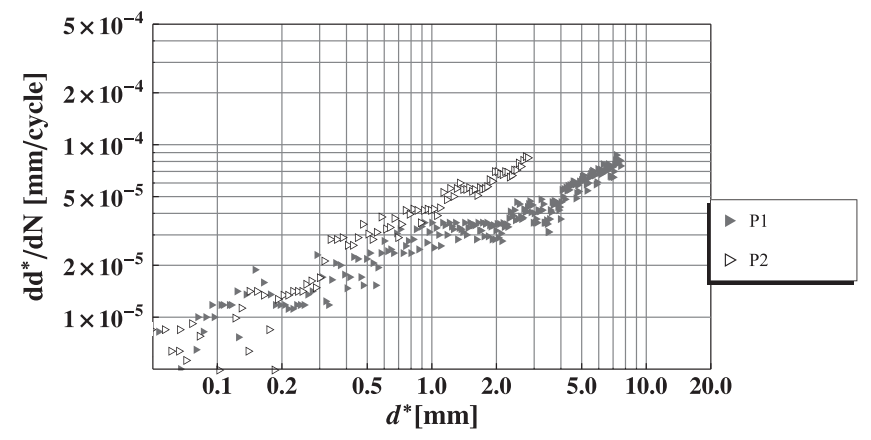

(a) Joint S6-J5N, tension brace side

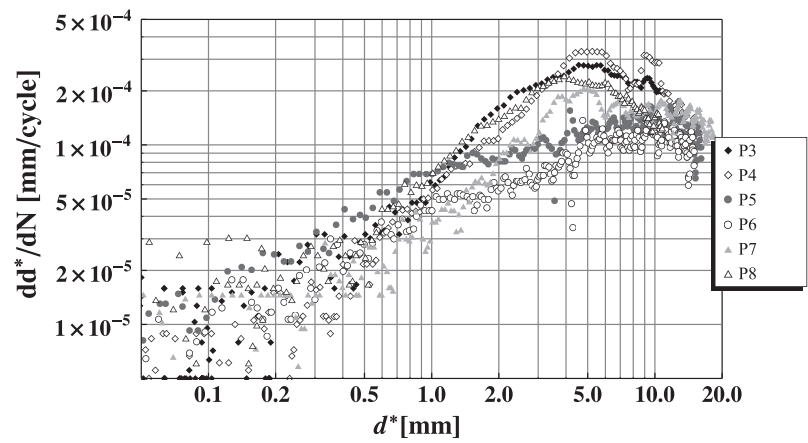

(b) Joint S6-J5N, compression brace side

Fig. 9. Measured crack propagation rates in joint S6-J5N as a function of the crack depth $d^{*}$ measured at different probe position along the crack length (log-log scale). 
brace side). Then, a crack starts to develop from hot-spot 1 (S6-J5N-probe1 at 25,000-30,000 cycles, tension brace side). The propagation rate increases on the tensile brace side whereas it decreases on the compressive brace side. This difference in the crack propagation rate evolution is also demonstrated in Fig. 7: an exponential increase is pointed at hot-spot 1 (S6-J5N-1, S7-J11) and a decrease at hot-spot 1c (S6-J5N-1c, S7-J5N-1c).

In Fig. 9, the inflexion point of the curve corresponds to a crack depth $d^{*}$ of the order of $5 \mathrm{~mm}$ in the crack plane (or $4 \mathrm{~mm}$ in the vertical plane). At that point, tensile residual stresses become smaller as seen in Fig. 1. Therefore, cracks on the sides of tension and compression braces continue to grow with different rates.

\subsection{Fatigue strength estimation}

In Fig. 6, an unexpected result is clearly seen: details loaded under fully- or part-compressive loading in tests do not have a different behavior than details loaded under tension. This figure proves that details in compression are not safer than others.

To simplify the fatigue life estimation for details loaded in compression, it is proposed to assume conservatively that the applied stress range is entirely tensile. Then, details with $\gamma<12$ loaded in both tension or compression can be designed with detail category 100 , taking the applied stress range as $S_{\text {rhs }}$ value. The fact that details in compression did not reach the through-thickness failure criterion is discussed below. The detail category 100 estimates more accurately the effect of size on the fatigue strength of welded tubular joints. It is more consistent with the hot-spot fatigue $S-N$ curve category 100 proposed in the IIW and Eurocode 3, Part 1-9 annex B for full penetration welds carrying loads. In order to keep the same predicted resistance (known to be reliable) and compensate for the overestimated SCF, the SCF values given in CIDECT and IIW guidelines have to be reduced. A reduction factor of 100/114 applied to formulas for SCF could be an elegant solution to update the CIDECT and IIW recommendations.

To make the distinction between the consequences of fatigue cracks in details loaded in tension and compression, a partial resistance factor $\gamma_{\mathrm{Mf}}=1$ is chosen for details in compression (damage tolerant design, low consequence of failure according to in Eurocode 3, Part 1-9) and $\gamma_{\mathrm{Mf}}=1.35$ for details in tension (safe life, high consequence of failure).

It is worth noting that in Fig. 6, some corrected values fall well above the design curve, especially the ones related to joints with $30 \mathrm{~mm}$ chord wall thickness. The size effect is not perfectly corrected with the correction factor used in this study [2]. Also, the tests with non-proportional sizing, i.e. series S5, are not corrected as well as other series.

\section{Conclusions}

Two fatigue tests are performed on large-scale specimens, representative of typical bridge construction. Crack development is followed in the welded tubular K-joints in order to determine the influence of the tensile residual stresses on fatigue behavior. Experimental investigations on the tubular truss specimens are carried out with a load ratio $R=0.1$. Therefore, details in tension are tested almost under zero-tension loading $(R=0.1)$ and details in compression under almost zero-compression loading $(R=10)$. The following conclusions can be drawn from the present study:

- Cracks occurring at hot-spot 1 under fully-tensile loading are driven by applied stresses, especially the proportion of brace stresses, influencing the crack shape, the propagation rate and the stress intensity factor. The residual stress field does not affect the fatigue crack growth in details loaded in tension.
- Cracks occurring at hot-spot 1c under fully-compressive loading are due to the presence of high tensile residual stresses making the fatigue cycle partly or entirely effective to crack propagation. Based on Alternating Current Potential Drop measurements (ACPD), it is shown that the stress intensity factor range remains highly positive within the range of measurement depths (up to $15 \mathrm{~mm}$ ). Therefore, in tested $\mathrm{K}$-joints, tensile residual stresses play a significant role in fatigue crack propagation since they enable cracks to propagate up to at least half of the chord wall thickness under applied compressive stresses.

- Cracks occurring at hot-spot 1 under part-tensile loading or at hot-spot $1 \mathrm{c}$ under part-compressive loading are more complex to analyze since they show a transitional behavior between tensile and compressive loadings. Despite this fact, their fatigue strength is not significantly better than the details under fully-tensile loadings.

- It is seen from test results that, if through thickness cracking is considered as the fatigue failure criterion, details loaded in compression are not the first to fail. The critical cracks are located at hot-spot 1 for each test, in joints combining the highest hot-spot stress range with the highest proportion of brace stresses. However, if the failure criterion is the half-thickness crack, details loaded under compression also reach that criterion at about the same number of cycles. The half-thickness crack, propagated under tensile residual stresses and compressive applied loads, may continue to propagate and cause the failure of the joint. Therefore, details in compression are not safer than the others and have to be designed in fatigue.

To be consistent, which is not the case for the failure criterion in the codes, a strength curve $S_{\text {rhs }}-\mathrm{Nf}$ category 100 for $T=16 \mathrm{~mm}$ is recommended to design all (tension or compression) CHS K-joints with $\gamma<12$. Note that the size effect correction from CIDECT have to be applied to use this curve. On the loading side, the hot-spot stress range should be determined with the correct real SCF and taken as the total applied hot-spot stress range. For consistency again, a distinction between the failure consequence of fatigue cracks in details loaded in tension and compression is made through the partial strength factor value (according to Eurocode3, Part 1-9): $\gamma_{\mathrm{Mf}}=1$ for details in compression and $\gamma_{\mathrm{Mf}}=1.35$ for details in tension.

\section{Acknowledgments}

This work was funded by the Swiss National Science Foundation (SNF). The tubes used for specimens were supplied by Vallourec and Mannesmann Tubes, Germany and the manufacturing of the large-scale specimens was performed by Zwahlen and Mayr, Switzerland.

\section{References}

[1] Zhao XL, Herion S, Packer JA, et al. Design guide for circular and rectangular hollow section joints under fatigue loading. CIDECT; 2000.

[2] van Wingerde AM, van Delft DRV, Wardenier J, Packer JA. Scale effects on the fatigue behaviour of tubular structures. In: IIW Proc; 1997.

[3] API. Recommended practice for planning, designing and constructing fixed offshore plattforms. Washington, USA; 2000.

[4] Hobbacher A. Recommendations for fatigue design of welded joints and components. Doc. XIII-1251-07, XV-1254-07, IIW; 2007.

[5] Gurney T. Fatigue of welded structures. Cambridge Univ. Press; 1979.

[6] Smith I, Smith R. Defects and crack shape development in fillet welded joints. Fatigue Eng Mater 1982;5:151-65.

[7] Barsoum Z, Samuelsson J. Fatigue assessment of cruciform joints welded with different methods. Steel Res Int 2006;77:882-8.

[8] Gurney TR. The influence of thickness on fatigue of welded joints. In: 8th International Conference, Offshore Mechanics \& Arctic Engineering.

[9] EN 1993-1-9:2005, Eurocode 3: Design of steel structures. Part 1-9: Fatigue; 2005. 
[10] Acevedo C. Influence of residual stresses on fatigue response of welded tubular K-joints. PhD thesis 5056, EPFL, Lausanne; 2011.

[11] Acevedo C, Nussbaumer A. Influence of welding residual stresses on stable crack growth in tubular k-joints under compressive fatigue loadings. In: ISTS13.

[12] Stacey A, Barthelemy J, Leggatt R, Ainsworth R. Incorporation of residual stresses into the SINTAP defect assessment procdure. Eng Fract Mech 2000;67:573-611.

[13] Bouchard P. Validated residual stress profiles for fracture assessments of stainless steel pipe girth welds. Int J Pres Ves Pip 2007;84:195-222.

[14] Schumacher A, Nussbaumer A. Experimental study on the fatigue behavior of welded tubular k-joints for bridges. Eng Struct 2006;28:745-55.

[15] Nussbaumer A, Borges L. Experimental determination of stress intensity factors on large-scale tubular trusses fatigue tests. In: ISTS 12, Shanghai.
[16] B. Standard Institute BSI, BS 7910:1999. Guide on methods for accessing the acceptability of flaws in metallic structures; 2000.

[17] Schumacher A, Sturm S, Walbridge S, et al. Fatigue design of bridges with welded circular hollow sections. Report ICOM 489E, EPFL; 2003.

[18] Dover WD, Monahan CC. The measurement of surface breaking cracks by the electrical systems acpd/acfm. Fatigue Fract Eng M 1994;17:1485-92.

[19] Barsom J, Rolfe S. Fracture and fatigue control in structures; 1987.

[20] Zhao XL, Packer JA. Fatigue design procedure for welded hollow section joints. IIW Doc. XIII-1804-99, XV-1035-99; 2000.

[21] Paris P, Erdogan F. A critical analysis of crack propagation laws. Trans ASME Ser D 1963:85:528-34.

[22] Bremen U. PhD thesis. Lausanne: EPFL thesis 787; 1989. 